\title{
Construindo saberes, controlando o corpo
}

\section{Building knowledge, controlling the body}

\author{
Gabriel Verdin de Magalhães \\ Mestrando do Programa de Pós-graduação em História/Universidade Federal de Minas Gerais. \\ gabrielverdin@hotmail.com
}

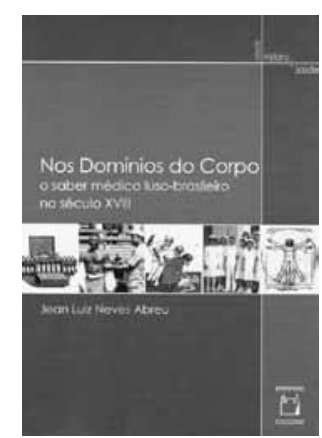

ABREU, Jean Luiz Neves. Nos domínios do corpo: o saber médico lusobrasileiro no século XVIII. Rio de Janeiro: Editora Fiocruz, 2011. 220p.

$\mathrm{O}$ corpo não nasce pronto. A conhecida afirmação das ciências biológicas ajusta-se perfeitamente à análise do corpo como uma construção histórica. Essa é uma elaboração cultural passível de transformações, permeada por concepções diferentes sobre a natureza e o funcionamento do corpo. Não se trata somente de padrões estéticos ou da não adequação a eles mas, muito além disso, das construções culturais que, a partir das mais variadas orientações, estabeleceram em determinados períodos históricos critérios sobre o que é saúde, doença e funcionamento normal e anormal do corpo humano.

Jean Luiz Neves Abreu apresenta ao leitor Nos domínios do corpo: o saber médico luso-brasileiro no século XVIII, obra que busca compreender essas construções. $\mathrm{O}$ autor analisa o pensamento médico luso-brasileiro no século XVIII, caracterizado pela multiplicidade de concepções de mundo, marcada pela convivência, nem sempre conflituosa, entre religião e razão. Isso insere o seu trabalho na história cultural das ciências, como aponta Betânia Gonçalves Figueiredo no prefácio da obra.

O livro resulta de uma adaptação da tese de doutorado em história defendida no Programa de Pós-graduação da Universidade Federal de Minas Gerais, sob orientação de Adriana Romeiro. A publicação da tese em formato de livro merece elogios. A clareza e objetividade de Jean Abreu oferecem uma leitura prazerosa mesmo para os que não estão familiarizados com a escrita acadêmica. Isso sem abandonar as referências e o uso de diversas fontes exigidos em uma tese de doutorado. Essa é marca recorrente nas produções da coleção História e Saúde, da Editora Fiocruz.

Ao tratar da construção do saber médico luso-brasileiro, o autor refuta a ideia de atraso atribuída pela historiografia à concepção portuguesa de ciência e medicina. Apoiando-se principalmente em Ribeiro (2003) e Villalta (1999), Jean Abreu demonstra que a tradição política e religiosa portuguesa, apesar de criar obstáculos para uma possível mudança das práticas e dos saberes médicos lusitanos, não fez com que a comunidade médica e científica 
de Portugal ignorasse as transformações ocorridas além-pirineus. Esse é um importante posicionamento do autor, pois, dessa forma, sua análise parte de uma concepção que entende a ciência não como neutra ou imparcial, mas sim como uma construção vinculada à cultura $\mathrm{e}$ à sociedade. Além disso, sua análise não hierarquiza os saberes qualificando-os como melhores, avançados, ou piores, atrasados.

É possível perceber que a disputa científica e os conflitos entre as diversas correntes de pensamento marcam a heterogeneidade do saber médico português no século XVIII. O ensino de anatomia foi um importante objeto de discussão do período, tendo mobilizado diversos sujeitos, engajados tanto na mudança quanto na manutenção da tradição médica lusitana. Tal disputa decorria do fato de existir, já no Setecentos, diferentes concepções da medicina, como ciência e como técnica. Jean Abreu aponta para as tentativas por parte dos médicos denominados letrados, de desqualificar aqueles que se prestavam ao ofício prático, denominados cirurgiões. Para embasar sua análise, o autor utiliza fontes como tratados médicos e ensaios. Sobre o letrado Nuno Marques Pereira, que publicou sua obra em 1728, Jean Abreu afirma que

Ao mesmo tempo em que associava a medicina a um ofício nobre, ... condenava os cirurgiões, porque "não satisfeitos em usarem suas artes, se querem a intrometer a darem razões de físicos, por talvez terem lido alguns livros romancistas, que ensinam algumas regras da medicina". Em razão de seu desprezo por aqueles que lidavam com o sangue e trabalhavam com as mãos, dizia desprezar o trabalho dos "anatômicos indoutos", comparando-os a carniceiros com um "verdugo na mão" (p.26).

O autor atribui a desqualificação dos cirurgiões pelos letrados à tradição portuguesa, que associava o trabalho manual à escravidão. Além disso, demonstra que a estrutura de ensino nas artes de curar privilegiava essa perspectiva pois, para tornar-se cirurgião, o indivíduo não necessitava formar-se pela universidade, símbolo de distinção entre grupos sociais lusitanos.

Os conflitos decorrentes do que o autor identificou como 'estrangeirados' e 'peripatéticos' proporcionou a reforma dos estudos médicos em Portugal no século XVIII. Os 'estrangeirados', segundo o autor, seriam aqueles que se aproximavam das concepções médicas além-pirineus, buscando aproximar prática e arte médica. 'Peripatéticos' seriam os que acreditam que o verdadeiro conhecimento é adquirido somente por meio dos livros, desvinculando a prática da arte médica.

É importante destacar que o autor trabalha com uma noção de ciência permeada por aspectos culturais, sociais e políticos, demonstrando as afinidades entre a história das ciências e a história cultural.

Jean Abreu preocupa-se não somente com os mecanismos sociais e políticos que são instrumentalizados para a construção de um novo saber médico, mas apresenta aspectos das concepções sobre o corpo em curso no século XVIII. Os saberes aquém e além-pirineus são analisados como uma 'visão direcionada de mundo', apoiada por coletivos que criam, recriam e sustentam percepções de mundo em interação com a sociedade.

Em meio à enorme variedade de concepções sobre o corpo, duas são destacadas pelo autor: uma que entendia o corpo humano como um 'microcosmo' e outra que o compreendia como 'máquina'. A primeira, fortemente influenciada pela tradição hipocrático-galênica, estabelecia analogias entre o corpo humano e o universo. De acordo com ela, "o universo compunha-se 
por três partes - mundo intelectual, mundo celeste e mundo elementar" (p.54). No homem, o mesmo ocorria, sendo 'a cabeça', 'o meio' e 'o interior', partes hierarquizadas que seriam suscetíveis a uma ou outra doença se o macrocosmo (universo) e o microcosmo (corpo humano) não estivessem em situação de correspondência exata. Já a segunda concepção entendia o corpo como um instrumento do homem. Cada parte do corpo teria uma função específica, sem hierarquias. Essas partes seriam os órgãos, artérias, veias e ossos. Tal visão, tributária dos estudos de anatomia, foi possível, entre outros fatores, pela concepção cartesiana que separa a consciência do homem de seu corpo, comparado-o à relógios, chafarizes e outras máquinas que possuíam mecanismos fragmentados.

Abreu fundamenta a relação do olhar com a anatomia em Foucault, autor que atribui importância, na emergência da medicina moderna, à mudança do olhar e à possibilidade de se olhar o interior dos corpos. Alguns preceitos foucaultianos são moderadamente trabalhados e incorporados à análise da autoridade conquistada pelos médicos e do controle que eles exercem sobre os hábitos dos indivíduos. Os saberes médicos estabeleceram regras de alimentação, sexualidade e educação física, garantindo assim um controle sobre o corpo dos indivíduos.

O uso da teoria e, em certa medida, da metodologia do microbiologista polonês Ludwik Fleck é um dos pontos altos do livro. É possível perceber como a obra de Fleck (2010), Gênese e desenvolvimento de um fato científico, influenciou a análise de Abreu. Em ambas as obras, o conhecimento científico é caracterizado como uma construção, historicamente condicionada, de diversos sujeitos que possuem linguagens distintas de codificação do mundo.

A escolha de Gênese e desenvolvimento como referencial possibilitou que Jean Abreu considerasse as transformações do saber médico luso-brasileiro não lineares e multidirecionais; entendendo-as, assim, como a convergência e assimilação de diferentes estilos de pensamento em um determinado contexto. O autor não julga que mudanças drásticas de 'paradigmas' derivem de transformações na percepção que a comunidade científica tem do mundo e das pessoas. Antes, concebe essas mudanças como resultado da confluência de estilos de pensamento, constituídos a partir da relação da comunidade científica com a sociedade, cultura e religião. Essa perspectiva, portanto, aproxima-se mais de uma ideia de evolução ${ }^{1}$ do que de revolução.

Em sua conclusão, Abreu (p.183) afirma:

Pode-se constatar, portanto, a recorrência de 'estilos de pensamento' diferenciados na forma de interpretar as doenças no contexto em estudo. Dessa maneira, em vez de tratar as influências da magia, da astrologia e do hipocratismo na medicina luso-brasileira como evidência do atraso científico, pretendeu-se indicar a existência de diferentes perspectivas de saber e suas formas específicas de objetividade. Assim, procurou-se evitar um olhar anacrônico em torno da medicina da época.

O livro Nos domínios do corpo: o saber médico luso-brasileiro no século XVIII, de Jean Luiz Neves Abreu, é uma importante leitura para estudiosos que se interessam por esse período, para os que analisam as práticas de cura 'oficiais' e populares, para historiadores das ciências e das culturas, assim como para quem procura uma leitura prazerosa sobre temas importantes da história luso-brasileira. 
NOTA

${ }^{1}$ Entendemos evolução de acordo com a proposta de Fleck (2010). A evolução para esse autor não segue um sentido positivo. Sendo assim é possível considerá-la processos de mudança que não necessariamente implicam melhora.

\section{REFERÊNCIAS}

FLECK, Ludwik.

Gênese e desenvolvimento de um fato científico. Belo Horizonte: Fabrefactum. 2010.

RIBEIRO, Márcia Moisés.

Exorcistas e demônios: demonologia e exorcismo no mundo luso-brasileiro. Rio de Janeiro:

VILLALTA, Luiz Carlos.

Reformismo ilustrado, censura e práticas de leitura: usos do livro na América portuguesa. Tese (Doutorado) - Faculdade de Filosofia e Ciências Humanas, Universidade de São Paulo, São Paulo. 1999.

Campus. 2003. 